\title{
Deleuze em Diálogo com Frémont: TENTATIVAS DE LER LeIBNIZ ${ }^{1}$
}

Gonzalo Montenegro ${ }^{2}$

RESUMO: Durante os anos oitenta, o filósofo francês Gilles Deleuze se concentra na leitura do pensador alemão do século XVII, G.W. Leibniz. Como resultado, publica em $1988 \mathrm{Le}$ Pli, obra que forma parte da série de estudos dedicados à filosofia moderna. Nela, evidencia-se, no entanto, como em nenhum outro estudo, a atenção de Deleuze a respeito das interpretaçōes dos comentadores contemporâneos da filosofia moderna, nesse caso, da filosofia leibniziana. Surge, assim, um diálogo com Christiane Frémont, comentadora e tradutora de Leibniz para o francês. Considerando esse breve, porém importante, diálogo sustentado por Deleuze e Frémont sobre as suas respectivas interpretaçôes de Leibniz, tenciona-se nesta pesquisa dar conta dos principais tópicos presentes na referida conversa. De forma preliminar, podemos dizer que esses tópicos envolvem: (1) o problema do corpo e do vinculum substantiale, (2) a questão das singularidades, (3) o princípio de economia e a incompossibilidade, e (4) o conceito deleuziano de vice-dicção. A hipótese que conduz nosso estudo é que as leituras feitas por ambos a respeito do pensador alemão estáo mutuamente entrelaçadas. É fundamental, assim, para apoiar essa hipótese, fazer a demarcação precisa das relaçóes entre tais leituras. Para tanto, nosso artigo se concentra fundamentalmente no estudo das obras Singularités, individus et relations dans le système de Leibniz (2003), de Frémont, e Le Pli (1988), de Deleuze. Dessa forma, esperamos determinar os tópicos principais que emergem do diálogo e, ademais, precisar as convergências e divergências de interpretação que se apresentam.

PALAVRAS-CHAVE: Gilles Deleuze. Christiane Frémont. Corpo. Singularidade. Incompossibilidade. Vice-dicção.

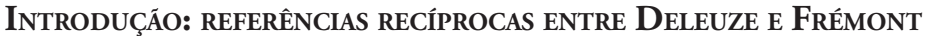

Na nota 49 do Prefácio de sua obra Singularités, individus et relations dans le système de Leibniz (FRÉMONT, 2003, p. 34, doravante SIR), Frémont dedica um importante comentário a Deleuze, que diz respeito à configuração

\footnotetext{
${ }^{1}$ Este artigo é resultado da pesquisa de Pós-Doutorado, intitulada Tópicos da relação entre Gilles Deleuze $e$ Christiane Frémont na leitura de Leibniz visando o estudo do conceito de vice-dicção, financiada pela FAPESP (Processo 2012/22195-5), realizada na Unesp de Assis, sob a supervisão do Prof. Hélio Cardoso Jr (Unesp, Assis) e cossupervisão da Profa Déborah Danowski (PUC-Rio).

http://dx.doi.org/10.1590/S0101-31732016000200008

2 Doutor em Filosofia pela Universidade do Chile. Professor do Instituto Latino-Americano de Economia, Sociedade e Política (ILAESP), da Universidade Federal de Integração Latino-Americana (UNILA) em Foz do Iguaçu - PR. E-mail: gozznl@gmail.com.
} 
da ideia de vice-dicção na obra de Leibniz (DELEUZE, 1968, p. 245; DELEUZE, 1988, p. 79). Dessa ideia, aliás, depende a tese central do livro, no qual ela tenta mostrar a inclusão complexa que exprimem diversos casos no contexto geral do sistema monadológico. A autora chama a atenção para certas tensóes que persistem entre a singularidade da mônada e o sistema de monadologia. Para isso, ela deve fazer uma leitura local dos problemas relativos à configuração de cada um dos casos singulares que estuda. Contudo, precisa determinar, também, a inclusão ambígua desses casos no sistema geral. A inclusão é ambígua, pois envolve uma dependência a respeito dos princípios que regem o sistema, mas também uma exceção para tais princípios. Por isso, segundo ela, esses casos constituem uma singularidade.

A referência ao conceito deleuziano de vice-dicção, a partir do qual Frémont explica aquela inclusão, coroa um fecundo, ainda que breve, diálogo entre ambos os pensadores, a propósito de suas respectivas interpretaçóes de Leibniz. O começo do diálogo pode se situar em 1981, quando Frémont publica parte da correspondência do pensador alemáo com o teólogo Barthélemy Des Bosses (1706-1716), precedida de um estudo titulado Lêtre et la relation (FRÉMONT, 1999, p. 13-77). Nessa pesquisa, ela sublinha o caráter problemático que envolve, para Leibniz, a formulação da ideia de substância composta, situação que procura superar por intermédio da atraente tese do vinculum. O vinculum substantiale representa a unidade que garante a substancialidade dos corpos. Vale lembrar que o próprio Leibniz $(1988, \$ 12)$ estimava que estes tinham apenas uma simples realidade fenomênica, a qual podia ser reduzida às percepçóes internas de uma substância individual. Com o vinculum, Leibniz (1999, Lettre 11/03/1706) tenta justificar a realidade do composto para além dos fenômenos e, ao mesmo tempo, visa distingui-lo do mero agregado material.

Deleuze se mostra especialmente sensível diante desse assunto, no capítulo VIII de Le Pli (1988). Poder-se-ia sustentar, com efeito, que essa parte da obra contém uma verdadeira doutrina deleuziano-leibniziana sobre o corpo, paralela àquela mais conhecida que o francês desenvolve, apoiado em Spinoza (LAERKE, 2001). A peculiaridade dessa proposta baseia-se em um diálogo abrangente com diversos autores contemporâneos, a fim de estudar os diferentes níveis do problema colocado por Leibniz e revisitado por Frémont. Isso permite a Deleuze realizar um tratamento heterodoxo de questôes tais como a relação hierárquica entre mônadas ou a pertença do corpo, que 
Frémont estuda exclusivamente desde o prisma da unidade substancial que outorga o vinculum.

Mais tarde, em 1991, Frémont escreve uma detalhada recensão de Le Pli, intitulada Complication et singularité (FRÉMONT, 1991). No texto, a autora analisa os casos ou singularidades propostas na obra de Leibniz, aos quais Deleuze dedica parte importante de seu estudo. São abordados relatos como os de Sextus Tarquínio, Adão ou César; os que Leibniz cita ao longo da sua obra, cujos detalhes aprimora principalmente em Theodicée (1710). Apesar da relativa dureza com que Frémont se expressa em certas passagens da recensão, e aparentemente não havendo resposta do autor de Le Pli, ressalta a ampliação do comentário dedicado a Deleuze, desta vez em SIR (2003). Aqui, a autora não se concentra somente em suas diferenças com Deleuze. Ao contrário, ela vai mais longe e considera as contribuiçôes presentes em Différence et répétition (1968). Eis que ela comenta as virtudes da abordagem deleuziana do conceito de vice-dicçáo acima descrita.

Vale salientar que Frémont publica uma segunda edição da correspondência entre Leibniz e Des Bosses em 1999. Além da correção de detalhes, ela acrescenta mais duas cartas redigidas por Leibniz. Entretanto, o que parece mais interessante é a ampliação da conclusão do seu estudo preliminar L'être et la relation. Nesse ponto, Frémont anuncia a publicação de SIR e enfatiza o caráter singular da tese do vinculum no contexto geral do sistema leibniziano. A autora indica que da mesma forma que as singularidades, o vinculum representa uma instância singular difícil de encaixar no sistema, mas sem a qual este ficaria incompleto (FRÉMONT 1999, p.76-77). Ela aproxima, assim, o lugar do vinculum ao estatuto ambíguo que a comentadora tenta pensar justamente a partir do conceito deleuziano de vice-dicçáo em $S I R$. Trata-se, sem dúvida, de um gesto de aproximação relevante para medir sua relação com Deleuze.

Com base no tecido de referências descrito, nosso artigo objetiva descrever os momentos mais importantes do diálogo entre Deleuze e Frémont. Para tanto, esperamos identificar as divergências e convergências presentes nos tópicos que dominam a relação entre ambos os autores, a saber: o corpo, o conceito de singularidade, o princípio de economia e a noção de incompossibilidade e, por último, a vice-dicção. 


\section{Corpo e Vinculum substantiale}

O vinculum é a relação que substancializa a composição característica do corpo. Nesse sentido, representa uma concepção do corpo bem determinada, que Leibniz desenvolve no final da sua carreira intelectual, principalmente na correspondência com Des Bosses. Com esse conceito, Leibniz objetiva proporcionar uma justificação metafísica que permita evitar o risco de reduzir os corpos aos fenômenos de percepção interna que definem a substância.

Como sabemos, a filosofia leibniziana é conhecida pelo sistema que o autor apresenta em uma das suas últimas obras, intitulada Monadologie (1714). Para esse sistema, a realidade remete a uma multiplicidade de substâncias simples e únicas $(\$ 1,4,9)$, as quais refletem o universo inteiro e agem como espelhos de tudo o que há ao seu redor $(\$ 56,59)$. Leibniz as chama de mônadas ${ }^{3}$. No entanto, a relação entre estas se dá através de um princípio de percepção interna, que define sua simplicidade e representa seu ponto de vista singular (\$11-14). Conforme se produz a variação das percepçóes, define-se uma tendência que o alemão nomeia apetição (\$15). A rigor, as mônadas constituem uma perspectiva determinada sobre o universo. Não é necessário, em consequência, supor uma relação externa entre elas, porque, tratando-se de puras percepçóes, basta que estas estejam coordenadas entre si para a relaçáo existir. $\mathrm{O}$ sistema de monadologia baseia-se, de modo significativo, no denominado princípio de harmonia pré-estabelecida, para o qual a ordem do universo está previamente determinada ao momento da criação. O dito princípio garante, com efeito, que a variação das percepçóes internas de cada mônada esteja perfeitamente coordenada com o transcurso das outras (LEIBNIZ, 1988, $\$ 14$, 33; LEIBNIZ, 1881, $\$ 78-80)^{4}$.

Posto isso, a descrição do corpo se justifica pelas percepçóes internas da mônada. Contudo, é importante distinguir formulaçôes diversas no sistema leibniziano. Quase trinta anos antes da Monadologie, Leibniz elabora o que

\footnotetext{
${ }^{3}$ A incorporação do termo coincide com a reforma da concepção de substância que Leibniz realiza, quando introduz a ideia de força nos anos 1690 (LEIBNIZ, 1939 [1693]). Ora, o termo aparece pela primeira vez em uma carta de 1696 . Já o primeiro uso público é de 1698 , no texto intitulado De Ipsa Natura (FICHANT, 2000).

${ }^{4} \mathrm{O}$ princípio de harmonia pré-estabelecida é enunciado explicitamente por Leibniz, em 1695, na obra Système nouveau de la nature et de la communication des substances (LEIBNIZ, 1939), destinado a resolver o problema, em voga durante a modernidade, da relação entre corpo e alma. No fundo, Leibniz sustenta um paralelismo harmônico entre a ordem teleológica que rege a alma e a ordem mecânica que determina aos corpos. Dessa dimensão deriva o uso do princípio para explicar também a espontaneidade das substâncias que, desde o momento da criaçáo, se encontram coordenadas umas às outras.
} 
reconhece como a primeira grande enunciação de seu sistema filosófico (BELAVAL, 1962, p. 158-163). Trata-se do Discours de métaphysique, de 1686. Nessa obra, sintética tanto quanto a Monadologie, a definição da substância é diferente, pois o autor visa fundamentar seu caráter singular, com base na inclusão dos acontecimentos dentro da própria noçáo de substância $(\$ 9,13)$, gesto que, do ponto de vista da tradição, aproxima perigosamente substância e acidente. O termo mônada, por sua parte, ainda não é utilizado e, na época, Leibniz prefere o termo substância individual. Entretanto, em 1714, a singularidade da substância será descrita a partir da ideia de simplicidade e do princípio de percepção interna da mônada.

Há certa continuidade nas consideraçóes relativas ao estatuto dos corpos. Nas duas obras, eles remetem às percepções das substâncias. Sem embargo, o foco, com o qual Leibniz enxerga a constituição dos corpos, varia de uma à outra. No Discours, por exemplo, a relação entre substâncias conduz a uma preocupação por descrever seu estatuto fenomênico. Aliás, a preocupação de Leibniz consiste em evitar fazer dos corpos simples circunstâncias imaginárias da percepção, como no caso do arco-íris (LEIBNIZ, 1988, Lettre 14/07/1686; BELAVAL, 1962, p. 226-229). As relaçôes de exterioridade, quando baseadas em noçốes relativas à extensão, tais como magnitude, figura e movimento, não fornecem mais do que uma explicação dos corpos baseada na imaginação (\$ 12). Sua essência pode ser descrita somente quando o entendimento proporciona uma explicação amparada na relação de percepção existente entre as substâncias. Ademais, Leibniz acrescenta apontamentos relativos à relação entre o corpo e a alma, alvo principal do seu princípio de harmonia préestabelecida que, apesar de não ser ainda concebido como tal, já está presente na fundamentação do Discours 5 .

Monadologie introduz uma novidade relevante não estabelecida ainda no Discours: a constituição orgânica dos $\operatorname{corpos}^{6}$. Para tanto, descreve dois tipos de composto. De um lado, os amontoados (amas) ou meros agregados, os quais não passam a constituir uma unidade $(\$ 2)$. Do outro, os corpos dos

\footnotetext{
${ }^{5} \mathrm{O}$ parágrafo $\$ 14$ do Discours propóe a existência de uma correspondência ideal (entr'entendement) entre as substancias individuais. Na correspondência com Arnauld, onde debatem sobre as teses do Discours, Leibniz é muito mais explícito e propōe a hypothèse de la concomitance ou de l'accord des substances entre elles (LEIBNIZ, 1988, $\$ 33$ ) que, ao longo dos anos, constituirá o princípio de harmonia pré-estabelecida.

${ }^{6}$ Segundo indica Duchesneau (2010), a teoria do organismo é relativamente tardia na obra de Leibniz, pois aparece enunciada só durante os primeiros anos do século XVIII, junto à abordagem da teoria da mônada.
} 
viventes dotados de unidade orgânica. Nesse caso, o organismo se define como uma unidade vital cujas partes apresentam a mesma potencialidade funcional que pode ser atribuída ao todo. Leibniz afirmará que o organismo é uma máquina divina (diferente da artificial) na qual as partes divididas ao infinito são também máquinas $(\$ 64)$. Nesse ponto, a preocupação constante de Leibniz consiste em fazer com que a unidade dos corpos não seja apenas aparente como acontece com os simples agregados.

Os corpos pertencem a uma mônada e caracterizam os seres viventes. $\mathrm{O}$ corpo se caracteriza, agora, por uma série de mônadas hierarquizadas segundo a perspectiva da mônada dominante. As percepçóes que esta tem do universo proporcionam o critério de articulação que propicia a organização dos corpos. Ora, tratando-se de uma mônada que domina as outras, o corpo se compóe internamente de mais relaçóes hierárquicas de dominação. "Vê-se, pois, que cada corpo vivo tem uma Enteléquia dominante, que no animal é a Alma; porém, os membros desse corpo vivo estão cheios de outros viventes, plantas, animais, cada qual, ainda, com sua Enteléquia ou sua alma dominante."

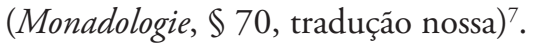

A correspondência com Des Bosses se estende por dez anos, nos quais a definição da hierarquia orgânica ocupa um espaço relevante. Mas, a conquista mais importante do debate filosófico empreendido com o jesuíta é enunciada em 5 de fevereiro de 1712, quando Leibniz formula pela primeira vez a hipótese do vinculum substantiale (lien substantial, vínculo substancial ou substantivante) ${ }^{8}$. A partir daí, inicia-se uma detalhada reformulação das diferenças com os simples fenômenos. Ao mesmo tempo, surge um debate intenso para tentar estabelecer a natureza desse vínculo. Des Bosses propóe pensar em um tipo de composto derivado que chama de acidente absoluto. Leibniz, entretanto, considera insuficiente reduzir o vínculo a modos ou acidentes, pois, nesse caso, não se conseguiria assentar mais do que a conhecida realidade fenomênica referida à expressão recíproca (entr'expression) das mônadas e suas mudanças de percepção (Lettres 24/01/1713; Lettres 23/08/1713). Leibniz objetiva, no fundo, determinar as características de

\footnotetext{
7 "On voit par là, que chaque corps vivant a une entéléchie dominante qui est l'âme dans l'animal; mais les membres de ce corps vivant sont pleins d'autres vivants, plantes, animaux, dont chacun a encore son entéléchie, ou son âme dominante".

${ }^{8}$ Frémont traduz vinculum substantiale por lien substantial. Ao não traduzir pelo termo padrão substantiel, acaba por introduzir um neologismo que, através do sufixo tial, pretende sublinhar o papel ativo do vínculo (FRÉMONT, 1999, 41). Na tradução do termo para o português vínculo substancial, perde-se a valiosa distinção da comentadora. Daí nossa proposta do termo vínculo substantivante.
} 
uma unidade que não pode ser confundida com a articulação dos fenômenos, muito menos com a composição que resulta disso.

O filósofo alemão sustentará, aliás, o caráter não derivado do vinculum, o que leva a institui-lo como uma instância realizante do corpo (Lettre 29/04/1715). O vinculum, ao se definir como o elo (lien) substancial que atribui unidade ao composto, náo pode ser considerado, ele mesmo, um composto. Por isso, Leibniz assinala que se trata de uma forma substancial, cuja relação de predicação não encaixa na estrutura de inesão ${ }^{9}$, a qual define a relação entre a mônada e suas variaçóes. Nesse caso, o vinculum não seria nada mais do que um fenômeno derivado da percepção congruente de várias mônadas. Não obstante, o conceito do vinculum refere-se, mais exatamente, a uma forma de adesão sobreposta (superadditum, surajouté) ao composto, justificando sua unidade e, consequentemente, dotando-o de realidade substancial (BOHEM, 1962, 29-31; Lettres 26/05/1712; Lettres 16/06/1712).

Visto que Frémont traduz e comenta a correspondência entre Leibniz e Des Bosses, os apontamentos metodológicos, a seleção de cartas traduzidas e a compreensão que se tem, em geral, sobre o problema do vínculo em Leibniz, dependem em boa parte de seu trabalho. Deleuze, por sua vez, se mostra tributário a essa produção, nos trechos onde trata da questão em Le Pli. Todavia, o percurso da abordagem deleuziana permite apontar também contrastes de interpretação importantes. De fato, quando realizamos a comparação entre ambos, o que de início nos chama a atenção é a circulação livre e aparentemente arbitrária de Deleuze pelo corpus leibniziano. $\mathrm{O}$ francês não estabelece âmbitos temáticos bem determinados, nem períodos específicos na obra de Leibniz. No capítulo VIII de Le Pli, por exemplo, ele procura articular os diferentes momentos e propostas presentes no sistema para dialogar com alguns aspectos da filosofia contemporânea, notadamente com Gabriel Tarde.

Nesse horizonte, o vinculum possibilita a Deleuze organizar suas aproximaçóes à questão do corpo, cujos eixos seriam: 1) a pertença do corpo à alma, 2) a relação de possessão subjacente à pertença, 3) a organização hierárquica e de dominaçáo que cria o composto corporal e 4) a forma exterior ou adjacente a partir da qual o vínculo se relaciona com o conjunto das mônadas do composto. Em uma exposição densa e ambiciosa, o pensador mostra os desdobramentos que conduzem de um eixo a outro. Contudo,

\footnotetext{
${ }^{9}$ Utilizamos o mesmo neologismo que o tradutor de Le Pli, Luiz Orlandi, adota para o termo francês inhésion, nos trechos do capítulo VIII dedicados ao vinculum. Trata-se, evidentemente, de um termo próprio do domínio semântico relativo à condiçăo inerente de uma propriedade atribuída à mônada.
} 
exatamente no ponto em que atinge a teoria do vínculo e em que, portanto, declara de maneira explícita as virtudes do comentário de Frémont, Deleuze desenvolve um gesto em sentido contrário. $\mathrm{O}$ autor assenta a questão do vínculo sobre a descrição da dominação e, apesar de não confundi-los, desconsidera a cuidadosa e reiterada insistência da comentadora em separar a doutrina do corpo, baseada na ideia de organismo, da doutrina do vinculum substantiale, derivada da noção de unidade substancial (FRÉMONT, 1999, p. 37-42).

A separação entre a ideia de organismo e a doutrina do vinculum se infere rapidamente da leitura da correspondência. Outros comentadores, como Belaval (1962, p. 245-246), Bohem (1962, p. 24) e Blondel (1930, p. 67-69) ${ }^{10}$, salientam também a necessidade de evitar confusōes neste ponto. Deleuze, provavelmente, não desconhecia essas advertências. No entanto, o que mais parece lhe interessar é colocar a dominação em um nível metafísico capaz de constituir a motivação fundamental do vínculo. Há vínculo, porque existem relaçôes de pertença fundadas na capacidade de dominação de umas mônadas sobre as outras (DELEUZE, 1988, p. 49-52). Evidencia-se uma inclinação explícita pela metafísica tardeana, caracterizada por uma meditação profunda a respeito da constituição diferenciada e multíplice da realidade (TARDE, 1893, Cap. VI). Inspirado em Tarde, Deleuze chega, inclusive, a apresentar, como eixo da concepção leibniziana do corpo, a abolição da hegemonia do verbo Ser (Etre) e a substituição pelo Ter (Avoir). Em outros termos, veicula-se a transformação das questôes clássicas referidas aos atributos da substância através dos problemas relativos à pertença e à dominação na mônada (DELEUZE, 1988, p. 147; TARDE, 1893, Cap. VII). Deleuze oblitera, de forma ousada, a distinção fundamental da teoria do vínculo, qual seja, o fato de reconstituir uma doutrina da substância capaz de dar unidade e ser - ou seja, de realizar - ao composto corporal.

Evidentemente, isso transtorna a proposta de leitura de Frémont. Atentando ao debate entre Leibniz e Des Bosses, a comentadora salienta o papel substantivante do vínculo. $\mathrm{O}$ vínculo não é uma substância simples dentre as que constituem o composto orgânico, mas sim a realidade metafísica que garante a unidade real dos corpos.

\footnotetext{
${ }^{10}$ São relativamente poucos os comentadores que atribuem um papel relevante ao vínculo, dentro do sistema leibniziano. Frémont dialoga basicamente com esses três. Entretanto, Deleuze náo leva em conta Blondel, embora este tenha sido uns dos responsáveis por reabilitar o estudo da questão, em meados do século XX.
} 
Mônada dominante e substância composta são inseparáveis, mas [...] jamais tem se afirmado que a mônada dominante perfaça a unidade da substância composta. Isto porque, lógica e metafísicamente, ela não pode fazê-lo: pois a mônada dominante, como as outras mônadas, constitui certa representação do universo, mais distinta e, portanto, mais perfeita do que as outras $[\ldots]$ porém, ela não é senão uma representação a mais, não a unidade de todas as representaçóes. Ela se integra à multiplicidade em vez de perfazer sua unidade. (FRÉMONT, 1999, p. 37, tradução nossa) ${ }^{11}$.

Apesar de ser uma preocupação clara de Leibniz, com o intuito evidente de garantir as particularidades da concepção do vinculum (Lettre 26/05/1712), este náo parece táo preocupado quanto Frémont em separar os níveis correspondentes à mônada dominante do organismo e ao vínculo, respectivamente. Com efeito, a comentadora objetiva fazer circular as distinçôes aristotélicas que abrem a correspondência através de todo o diálogo. Dessarte, o eixo que define o vínculo depende do critério escolástico de definição da substância sobre o qual se debruçam as primeiras cartas de Leibniz, qual seja, a reciprocidade entre Ser e Um (Lettre 14/02/1706; FRÉMONT, 1999, p. 37). A partir dessa intuição fundamental, Frémont descarta a possibilidade de que o vínculo seja constituído por uma mônada em particular. Esta não faria mais do que adicionar multiplicidade ao composto por estar constituída, como o resto das mônadas do conjunto, por seu próprio ponto de vista. Dessa forma, Frémont tenta elucidar o sentido das figuras do Eco e da Parede, das quais Leibniz se vale para explicar a natureza do vínculo (Lettre 29/04/1715). A relação permanece exterior ao composto, na medida em que reflete o efeito em conjunto que gera a multiplicidade de mônadas. Ela afirma, por isto, que "[...] as mônadas são os emissores; o vinculum, a parede reflexiva; o substanciado, o eco mesmo" (FRÉMONT, 1999, p. 36, tradução nossa) ${ }^{12}$.

Ironicamente, trata-se das mesmas passagens que Deleuze lê, de modo inverso, conferindo o papel de parede reflexiva à mônada dominante. $\mathrm{O}$ autor reconhece que são duas coisas diferentes e indissoluvelmente ligadas. Sem embargo, isso não o leva a sustentar o caráter substantivo do vínculo.

\footnotetext{
11 "Monade dominante et substance composée sont inséparables, mais [...] il n'est jamais dit que la monade dominante fasse l'unité de la substance composée. Et ceci parce que logiquement, et métaphysiquement, elle ne peut le faire : car la monade dominante, comme les autres monades, est une certaine représentation de l'univers, plus distincte donc plus parfaite que les autres [...] mais elle n'est qu'une représentation de plus, non l'unité de toutes les représentations. Elle ajoute à la multiplicité au lieu d'en faire l'unitén. A tradução é nossa. Doravante, todas as citaçōes de Frémont corresponderão a nossa tradução.

${ }_{12}$ "[...] les monades sont les émetteurs, le vinculum la paroi réfléchissante, le substantié l'écho lui-même».
} 
Seria, de fato, contraditório, depois de ter proclamado a morte do verbo Ser e a introdução, no seu lugar, das relações de pertença características do Ter. Deleuze transforma o vínculo em uma forma de exterioridade que determina à mônada dominante. Para tanto, examina os efeitos de conjunto próprios das variaçôes das mônadas que compóem um corpo como multidóes (foules). Nesse momento, a mônada dominante se descola do conjunto e assume o papel de exterioridade constante, a respeito dessas variaçôes: “[...] o próprio vínculo é que é 'parede reflexiva' e ele o é por ser essa forma do fora que depende da [mônada] dominante ou constante" (DELEUZE, 1991 [1988], p. 168) ${ }^{13}$.

Uma vez que as diferenças estudadas versam sobre os aspectos mais importantes da obra da comentadora, seria lógico que Complication et singularité incluísse esclarecimentos ou até uma certa oposição ao tratamento das questôes relativas ao corpo e ao vínculo propostas por Deleuze, em 1988. No entanto, isso não acontece, e Frémont se concentra nas diferenças que confrontam os autores, no horizonte do problema da novidade e da singularidade. Como indicamos anteriormente, ela valoriza as contribuiçóes do filósofo francês neste ponto, mas, ao mesmo tempo, é bastante crítica nas consequências da abordagem deleuziana para alguns dos princípios mais importantes do sistema.

\section{Singular E Singularidade}

Para assegurar a constituição singular da substância ou mônada, Leibniz cria o conhecido princípio de indiscernibilidade. Não há semelhanças que permitam estabelecer um conjunto específico de substâncias que as diferencie apenas pelo número (duas, três, quatro, $n$ substâncias iguais...). Aliás, se as notas que possibilitam descrevê-las coincidem, ao ponto de tornálas indiscerníveis, então se trata da mesma substância (LEIBNIZ, 1988, \$9; LEIBNIZ, 1881, \$8). Disto surge a necessidade de explicar as relaçóes que esta estabelece com o mundo, visto que a singularidade parece bloquear a determinação dos elos e articulaçóes que a vinculam com o entorno ${ }^{14}$. Nesse sentido, a noção de singularidade representa, para Deleuze e Frémont, um lugar importante para estudar as relaçóes dentro do mundo leibniziano, ao

\footnotetext{
13 "[...] c'est le vinculum lui-même qui est "paroi réfléchissante», et il est parce quil est cette forme du dehors qui dépend de la [monade] dominante ou constante" (DELEUZE, 1988, p. 150).

${ }^{14}$ A partir da influente leitura de Russell $(1900, \$ 23-27)$, esse problema será conhecido como a oposição entre os princípios de indiscernibilidade e de continuidade. Deleuze (1988, p. 28) e Frémont (1999, 2003), no entanto, abordam a questão de forma mais detalhada, sem pressupor que há simplesmente uma contradição.
} 
mesmo tempo em que descrevem o caráter único da mônada. "Eu chamo, portanto, de singularidades àquelas [mônadas] que provêm de uma bifurcação ortogonal a todos os mundos possíveis (inclusive o real), a qual é determinada num caminho que não pertence senão ao mundo escolhido." (FRÉMONT, 1991, p. 119, tradução nossa) $)^{15}$.

Para Leibniz, o mundo surge da escolha divina de um dos possíveis, do melhor dos possíveis, aliás. O entendimento divino idealiza infinitos mundos, cada um com uma constituição particular, dotado de substâncias diversas afetadas, por sua vez, por múltiplas circunstâncias. A vontade, orientada pelo princípio do melhor, escolhe o mundo a ser criado (LEIBNIZ, 1988, \$14; LEIBNIZ, 1881, $\$$ 48, \$53-55). Para Frémont, o âmbito relativo a essa escolha coloca Leibniz perante o estudo de uma diversidade de casos que apresentam as complicaçôes inerentes à criação do mundo. Assim sendo, ela julga necessário distinguir aqueles casos das mônadas restantes. Os casos extraordinários, chamados de singularidades, atravessam todos os mundos possíveis e, enquanto tais, encarnam o problema da criação (FRÉMONT, 1991, p. 118-120). Entretanto, o resto das mônadas somente faz parte do mundo possível ou real ao qual pertencem. Frémont (2003, p. 17) reserva para elas o termo singular: "[...] todo singular não é uma singularidade, embora esta requeira o singular." (tradução nossa). ${ }^{16}$

Surge aqui uma diferença importante com relação a Deleuze. Para a comentadora, o papel da singularidade na criação se reflete também na expressão da totalidade das relaçóes do mundo (FRÉMONT, 2003, p. 100103). Todavia, Deleuze afirma que a singularidade constitui apenas um ponto de inflexão local em uma série de regularidades. Isto o conduz a sustentar uma sorte de mot d'ordre na fórmula: «Tudo é ordinário! E tudo e singular!» (FRÉMONT, 1991 [1988], p. 137, grifo nosso) ${ }^{17}$. Frémont acredita que essa interpretação visa ao estabelecimento de relações horizontais no sistema ${ }^{18}$,

\footnotetext{
15 "J'appelle donc singularités celles [monades] qui procèdent d'une bifurcation orthogonale à tous les mondes possibles (le réel inclus), laquelle se détermine en un chemin qui n'appartient qu'au seul monde choisi" A mesma passagem pode ser encontrada em Frémont, 2003, p. 103.

16 “[...] tout singulier n'est pas singularité, quoique celle-ci requière le singulier".

17 “Tout est ordinaire et : Tout est singulier!" (FRÉMONT, 1988, p. 121).

${ }^{18}$ A relação de singularidade corresponde, em Deleuze, à diagonal ou transversal, e não à horizontal, como pretende Frémont. Segundo Deleuze, a distribuição vertical ou horizontal depende de coordenadas pré-estabelecidas em uma ordem global (DELEUZE, 1986, p. 34). Por isso, inclusive a explicação horizontal precisa de uma referência global. A diagonal, no entanto, almeja garantir a natureza local das singularidades, que depende apenas das relaçôes de vizinhança do singular (LAUTMAN, 1938; DELEUZE 1968, p. 230; DELEUZE, 1969, p. 127; DELEUZE 1988, p. 86 y ss.).
} 
caso em que desaparece qualquer possibilidade de hierarquia entre mônadas. A autora exalta essa estratégia em Deleuze, porém, não concorda com suas consequências, uma vez que, segundo ela, se perde o âmbito exclusivo reservado às singularidades e ao problema da criação. Na recensão de 1991, Frémont (1991, p. 105-112) identifica em Deleuze uma proposta interessante a respeito da questão da novidade, mas nesse mesmo campo acusa uma falta de atenção à escolha e criação divina do melhor dos mundos possíveis.

Essa diferença reflete ainda a compreensão de cada um sobre o conceito de singularidade. Para Frémont (1991, p. 115, 2003, p. 100-103), esta representa uma situação excepcional na qual ressoa a totalidade das relaçôes do sistema. A singularidade expressa a razão suficiente da criação e representa, por isso, o segredo da criação. Isso a conduz a demarcar uma diferença substantiva entre o caráter singular que tem toda mônada, enquanto definida por um ponto de vista individual, e a singularidade, mônada que tem um papel central na definição do sistema (FRÉMONT, 1991, p. 114; FRÉMONT 2003, p. 17).

Deleuze, entretanto, não distingue tais termos, e tentará sustentar uma relação sem privilégios relativos a qualquer mônada em particular. Dessa maneira, a identificação da singularidade depende de uma determinação relativa que não evidencia a característica permanente de nenhuma entidade específica. Para isso, analisa a variação da percepçáo da mônada. A introduçáo de uma dobra $(p l i)$ no desenvolvimento da variação estabelece um ponto de inflexão que pode ser entendido em dois sentidos. Primeiro, como singularidade interna que representa um acontecimento para a mônada. Segundo, como ponto de vista que se situa no ponto de inflexão definido pela dobra. A singularidade concebida como acontecimento ou como ponto de vista se define, portanto, pela série ou variação da qual faz parte (DELEUZE, 1988, p. 27-29).

Ora, neste ponto, convém ressaltar que a singularidade não coincide exatamente com a mônada. Trata-se, com efeito, de uma instância bem determinada dentro da série completa de variaçôes perceptivas que a constitui. Essa instância é capaz de definir, além disso, o ponto de vista que gera a marca singular de cada substância. $\mathrm{O}$ eixo da preocupaçáo deleuziana com a singularidade não diz respeito, como em Frémont, ao problema da criação, senão à determinação de instâncias pré-individuais dentro da série que compôe a variação perceptiva da mônada. Acreditamos, à vista disso, que Deleuze se serve simultaneamente das noçóes de substância individual e de mônada, pois leva em conta a ideia de uma série de acontecimentos, apresentada no Discours (\$9), e a noção de variação perceptiva, presente em Monadologie (LEIBNIZ, \$14-15). 
Cada instância da variação representa um acontecimento, ponto de inflexão ou singularidade. Contudo, se dermos atenção à série completa da variação, estaremos diante da constituição regular ou ordinária da mônada. A série completa, por sua vez, depende de relaçóes de continuidade ou vizinhança entre os diversos pontos de inflexão. Por essa razão, de acordo com Deleuze, as singularidades podem ser concebidas como pontos de inflexão préindividuais. Todavia, na medida em que tais instâncias se definem a respeito da série regular, elas são também resultados de um filtro perceptivo que compara as diversas percepçóes e identifica as mais relevantes (remarquables). Daí a afirmação circular que, primeiro, vai das singularidades ao decurso ordinário da série de acontecimentos ou percepçóes e, segundo, desprende, desta série regular, as instâncias notáveis que se destacam como singulares (DELEUZE, 1988, p. 120-121).

A diferença no tratamento da singularidade entre Frémont e Deleuze se associa, assim, a uma divergência profunda na abordagem da individuação em Leibniz. Em Frémont, há entidades completas constituídas no entendimento divino ao momento de este idealizar os infinitos mundos possíveis. Já Deleuze tenta esclarecer a gênese da mônada com base nos acontecimentos que descrevem o mundo no qual aquela surge. Se, para Frémont, a singularidade depende do problema da escolha e da criaçáo do melhor dos mundos, para Deleuze, o assunto remete ao âmbito da individuação da mônada no mundo.

Essa discordância resulta evidente em obras como Différence et répétition (DELEUZE, 1968, doravante DR) e Logique du sens (DELEUZE, 1969), nas quais utiliza livremente algumas referências do autor alemão para configurar sua própria filosofia. Em ambas as obras, são predominantes seu questionamento ao modelo de escolha divina e a separação entre o possível e o real que esta escolha produz. Assim sendo, Deleuze (1969, séries XV-XVI) sustenta a necessidade de compreender como reais tanto os acontecimentos virtuais pré-individuais (que chama de singularidades), quanto os indivíduos atuais já constituídos. O problema da diferença ou da novidade, que tanto preocupa Frémont, não remete em Deleuze à questão da criação. Ao contrário, ele coloca o problema da novidade ou, para ficarmos nos termos de $D R$, da diferença em duas instâncias: 1) na variação virtual que se prolonga na série de singularidades ou acontecimentos (différentiation) e 2) no processo de atualizaçáo que vai das singularidades, ou acontecimentos do mundo, aos indivíduos (différenciation) (DELEUZE, 1968, p. 269-287). O mundo não precisa ser criado, o que precisa acontecer é a gênese das individualidades no mundo. Para tanto, 
Deleuze se foca em temas caros também a Frémont, como a abordagem crítica do princípio de economia, e nos detalhes correspondentes ao fenômeno presente na composição do mundo, denominado incompossibilidade.

\section{PrincíPIO De ECONOMIA E INCOMPOSSIBILIDADE}

O princípio de economia leibniziano visa determinar a natureza da escolha divina do melhor dos mundos possíveis, em torno da determinação de um conjunto capaz de atingir, com um mínimo de leis, o máximo de diversidade no mundo. Trata-se de um dos pontos mais sensíveis do sistema leibniziano, já que garante a dupla função da criação divina: de um lado, a íntima conexão de tudo o que existe e, do outro, a variação e a diversidade da criação (LEIBNIZ, 1988, \$ 14; LEIBNIZ, 1881, \$57-58; LEIBNIZ 1939 [1697]). Ademais, o sistema mostra-se eminentemente hierárquico, no sentido de que o Deus criador representa a razáo suficiente da unidade e diversidade do conjunto criado (LEIBNIZ, 1939 [1697]). Nesse aspecto, a tentativa de interpretação de Frémont pode parecer temerária, pois atribui a razão suficiente a instâncias extraordinárias (singularidades) nas quais ressoa horizontalmente o todo da criaçáo. Entretanto, essa estratégia não questiona a importância do princípio de economia, já que o fortalece ainda mais. Com efeito, a comentadora identifica a possibilidade de ler, nos meandros da própria criação, os motivos da escolha do melhor dos mundos possíveis ${ }^{19}$.

A escolha do melhor dos mundos envolve uma avaliação das linhas de continuidade a serem estabelecidas na série dos possíveis. À medida que uma série oferece maior variedade dentro de um esquema de compatibilidade, ela é considerada melhor e mais perfeita. Leibniz denomina essa compatibilidade de compossibilidade. A criação de um mundo envolve a determinação da possibilidade conjunta de existência de múltiplas substâncias. Não se trata, apenas, de avaliar a criação de indivíduos dispersos, porém, da existência conjunta de todos os que comporiam um mundo determinado.

\footnotetext{
${ }^{19}$ Frémont salienta o papel da reflexão cristológica em Leibniz. O caráter singular e extraordinário da encarnação possibilita pensar o mistério da criação a partir de um modelo horizontal de relaçôes. Nesse caso, Cristo garante a unidade das substâncias através da comunhão dos corpos (via vinculum), substituindo a relevância central do princípio de ordem hierárquico, próprio da harmonia préestabelecida, a qual opera na versão tradicional do sistema leibniziano (FRÉMONT, 1999, p. 43-45). Blondel (1930) concorda, ao considerar que o sistema poderia ser reformulado com base na questão teológico-filosófica presente no vinculum.
} 
Ora, a avaliação da compossibilidade envolve também a determinação de instâncias de bifurcação em que a série não é contínua. $\mathrm{A}, \mathrm{B}$ e C são compatíveis, ou seja, são possíveis conjuntamente. Contudo, A, B, C, de um lado, e D, do outro, podem não ser possíveis na mesma série. Eis a existência de mundos possíveis diferentes, cuja incompatibilidade Leibniz chama de incompossibilidade (LEIBNIZ, 1978 [1680]). Uma vez que a incompossibilidade é o mecanismo analítico que permite distinguir os infinitos mundos possíveis uns dos outros, e a compossibilidade, determinar sua articulação interna, ambos os procedimentos lógicos são fundamentais para a escolha divina do melhor dos mundos. Dessa maneira, a incompossibilidade constitui um dos eixos fundamentais da criação. Com efeito, "[...] se trata de um grande mistério enterrado no entendimento de Deus" (DELEUZE, 1991 [1988], p. 94, traduçáo nossa) ${ }^{20}$, que, ao ver de Frémont, constitui o motivo pelo qual um mundo passa a existir e outro não (FRÉMONT, 2003, p. 109, n.12).

Um mundo tal renuncia à economia da integraçáo do múltiplo no um [...]. A vagabundagem de um elemento através de todas as séries implica a repetição: se o jardim dos sendeiros que se bifurcam existe, Fang - mas de que maneira seria o mesmo Fang? - deve se repetir quatro vezes em quatro séries dessemelhantes para que se produzam quatro acontecimentos disparates21: matar, não matar, ser morto, não ser morto. É necessário multiplicar, ou melhor, justapor as séries para mudar os efeitos: a despesa iguala a riqueza [...] Neguemos o princípio de escolha, e admitamos a existência (real e simultânea) de todos os incompossíveis leibnizianos: simulemos que a pirâmide inteira constitui um mundo. (FRÉMONT, 1991, p. 111-112, tradução nossa).22

Em $D R$ e $L S$, Deleuze se mostra particularmente interessado em questionar o cálculo que sustenta o princípio de economia que está por

\footnotetext{
20 "[...] c'est un grand mystère enfoui dans l'entendement de Dieu" (DELEUZE, 1988, p. 79).

${ }^{21}$ Seria mais simples traduzir pelo termo "díspares". No entanto, preferimos essa solução (só em aparência hiperbólica), para conservar o vínculo com o âmbito semântico da "disparaçáa" (disparation) simondoniana, obviamente presente na proposta de Deleuze, aqui submetida à crítica de Frémont. Veja-se Deleuze, (1968, p. 301-306).

22 "Un tel monde renonce à l'économie du (rem)plissage du multiple dans l'un [...]. Le vagabondage d'un élément à travers toutes les séries implique de la répétition: si le jardin aux sentiers qui bifurquent existe, Fang - mais en quoi est-ce le même? - doit se répéter quatre fois dans quatre séries dissemblables pour que se produisent quatre événements disparates: tuer, ne pas tuer, être tué, nềtre pas tué. Il faut multiplier, ou plutôt juxtaposer les séries pour changer les effets : la dépense égale la richesse [...] Nions le principe du choix, et admettons l'existence (réelle, simultanée) de tous les incompossibles leibnitiens: feignons que la pyramide tout entière fasse un monde».
} 
trás da criação. O autor afirma que todos os indivíduos e todos os mundos passam à realidade, tornando a incompossibilidade uma relação de disjunção interna ao mundo existente (DELEUZE, 1969, série XIV; LOPES, 2010; SIMONT, 1997, Cap. V). Deleuze confere, assim, um estatuto filosófico à ficção proposta por Borges, no conto "El jardín de los senderos que se bifurcan”. O protagonista é um espião às ordens do serviço secreto alemão que opera na Inglaterra. Quando é descoberto, foge até a casa de um amigo, um reconhecido sinólogo que lhe apresenta os vestígios da obra mítica de um velho antepassado, T'sui Pên. A obra consta de um romance que idealiza um labirinto no qual todos os mundos possíveis se realizam, o que acarreta vários desenlaces e cursos temporais divergentes. $\mathrm{O}$ que mais chama a atenção é o momento em que Fang, o herói desse romance, vive uma situação parecida à que atravessa o próprio espião: "Fang, digamos, tem um segredo, um desconhecido bate à sua porta, Fang resolve matá-lo. Naturalmente, há vários desenlaces possíveis. Fang pode matar o intruso, o intruso pode matar Fang, ambos podem salvar-se, ambos podem morrer" (BORGES, 2000, p.67). ${ }^{23}$

A fuga, para Deleuze, representa um transe em que atual e virtual se confundem: a individualidade do espião, aliás, se mistura com a do herói do labirinto. $\mathrm{O}$ espião experimenta uma variação de singularidades que o atravessa e o confunde com Fang e, através deste, o faz viver diferentes mundos possíveis (DELEUZE, 1968, p.15; DELEUZE, 1969, série XVI; MARTIN, 1993, II, p. 3). Esta é, evidentemente, uma interpretação ousada da filosofia do pensador alemão, já que o mesmo estima, ao contrário, que, dentre os diversos mundos possíveis, se realiza apenas um. Para Frémont, a tentativa de Deleuze conduz para um verdadeiro desperdício ontológico. O risco, segundo ela, está em que nasce um sistema para o qual os indivíduos e as séries completas que os incluem (os mundos) estão condenados a se repetir. Esse sistema, além de ser caótico e não oferecer condiçôes para a determinaçáo plausível do mundo real, desconhece o caráter alegórico da ficção, em Leibniz (FRÉMONT, 1991, p. 111; FRÉMONT, 2003, p. 110-112). Não obstante, Deleuze reflexiona com cuidado sobre as questôes relativas à repetição e ao caráter vago das entidades comprometidas na dualidade incompossível que as coloca em mundos divergentes. Para tanto, elabora uma concepçáo da diferença que explica como as singularidades virtuais submetidas à variação se atualizam, definindo as séries convergentes responsáveis da gênese da individualidade. Frémont identifica

23 "Fang, digamos, tiene un secreto; un desconocido llama a su puerta; Fang resuelve matarlo. Naturalmente, hay varios desenlaces posibles: Fang puede matar al intruso, el intruso puede matar a Fang, ambos pueden salvarse, ambos pueden morir" (BORGES, 1997, p. 75). 
uma evidente perversão do princípio de economia, mas esta perversão ocorre em maior parte na anulação das bases teológicas do que na incompreensão dos fenômenos econômicos comprometidos nos processos de repetição. Ao que parece, Frémont não atinge uma compreensão adequada das relaçôes entre diferença e repetição estudadas por Deleuze em $D R$, capítulos IV e V.

A grande virtude de $D R$ se resume na tese que concebe a repetição como um fenômeno característico da variação da diferença. Nesse sentido, o que se repete é sempre diferente. Como vimos acima, a concepção de singularidade deleuziana define a diferença como um fenômeno em variação constante, na qual cada inflexão representa um modo de a diferença se repetir. Fang, certamente, se repete, mas diferentemente em cada caso. Nesse ponto, Frémont acredita que deve se repetir, ou seja, atualizar, a série completa do mundo em que habita cada um dos diferentes Fang. Todavia, isso não representa mais do que uma forma de falar. A rigor, Fang não é um indivíduo, mas uma instância singular ou vaga, ainda náo constituída. Trata-se de um segmento de variaçôes ao qual o próprio espiáo é exposto. A singularidade, para Deleuze, é pré-individual e, como tal, só pode ser experimentada pelo indivíduo como uma variaçáo que questiona sua identidade. Desse modo, falamos em termos de mundos possíveis afetando a individualidade de Fang, porque adotamos a perspectiva do mundo atual constituído. Cada variação envolve outras variaçóes (a diferença se diferencia) e, nesse sentido, contém infinitos mundos. Trata-se, no entanto, de mundos virtuais cujas instâncias de desdobramento são singularidades, acontecimentos em variação, e não substâncias individuais que exigiriam cada vez a reconstituição diferente de um mundo inteiro.

A variação de singularidades é o mundo virtual que pulsa de forma disjuntiva em cada transformação. Somente a atualização, a qual constitui uma série regular completa e que, portanto, dá origem ao indivíduo, pode exigir desse mundo um mundo atual com entidades fixas que, obviamente, seria absurdo tentar repetir. O lugar da incompossibilidade em Deleuze se define exatamente aqui, no ponto de inflexão que vai da variação virtual de singularidades até a série regular de acontecimentos que definem o indivíduo. Leibniz se confronta a essa questão, quando discute a ideia de substância individual com Arnauld. A tese de um Adão vago, proposta pelo mesmo Leibniz em uma sorte de erro feliz, não faz sentido para um mundo com indivíduos constituídos. Um Adão que não peca simplesmente já não é Adão (LEIBNIZ, 1988, IX, remarques mai 1686). Deleuze leva a sério o erro leibniziano, ao estimar que uma noção vaga como essa possibilite pensar em instâncias 
singulares pré-individuais pelas quais atravessam os sujeitos constituídos nos transes de fuga. No conto, o mundo virtual inteiro faz vibrar a individualidade do espião, quando depara com o labirinto, levando-o a experimentar uma variação de acontecimentos que coloca em xeque sua própria existência: matar, não matar, ser morto, não ser morto.

O conto de Borges se assemelha a uma das ficçóes mais interessantes narradas por Leibniz, em Théodicée, a de Sextus Tarquínio na pirâmide. Nesse relato, Leibniz imagina um sacerdote, Teodoro, tentando compreender os motivos secretos pelos quais Júpiter anuncia um obscuro e difícil futuro a Sextus. Este recebe do deus a advertência de que, se voltar a Roma, acabará por violar Lucrécia, uma jovem da aristocracia, o que acarretará a expulsão dele e de toda a família real à qual pertence. Sextus ignora a mensagem de Júpiter e, ao voltar, se reconhece envolvido nos conflitos anunciados no templo. Guiado durante o sonho pela sabedoria de Palas, cuidador do Palácio de Júpiter, Teodoro aprecia uma pirâmide composta de infinitos quartos, cada um representando um mundo possível com diferentes caminhos para a vida de Sextus. Eis, acima da pirâmide, o quarto com a concatenação mais perfeita de acontecimentos, a série do mundo efetivamente criado por Deus (LEIBNIZ, 1900, \$405-415). No capítulo IV de SIR, Frémont reconhece o lugar central que, a respeito do princípio de economia, ocupa a pirâmide na ficção sobre Sextus. A pirâmide representa os infinitos mundos possíveis dentre os quais Deus escolhe o melhor. A pirâmide tem, assim, um vértice, mas não tem base, porque os mundos possíveis representados nos apartamentos são infinitos. Em consequência, o vértice representa, para Leibniz e para Frémont, o grau maior da sabedoria na escolha divina e o funcionamento adequado do princípio de economia (LEIBNIZ, 1939 [1697]; FRÉMONT, 2003, p. 108-110).

Entretanto, para Deleuze (1988, p. 169), o vértice é apenas o ponto atual que envolve a virtualidade infinita das outras locaçóes. Define-se aqui uma das diferenças mais importantes de Deleuze a respeito da doutrina leibniziana, porque as formas cônicas ou piramidais que o pensador alemão descreve são transformadas pelo francês em esquemas de análise da relação do atual com o virtual. Assim sendo, ele se desvia do propósito original, que era identificar graus de perfeição, seja de um mundo possível (LEIBNIZ, 1900, $\$ 414-415)$, seja dos tipos de conhecimento (LEIBNIZ, 1921, p. 408-421).

A posição de Deleuze, acreditamos, se explica pela recuperação do cone de Bergson. Para este, o vértice é apenas o grau atual de uma realidade que contém níveis diferentes de virtualidade (BERGSON, 1965, cap. III). Em 
consonância com sua crítica das categorias de nada e de possibilidade, Bergson estabelece que tudo, seja atual, seja virtual, é real (BERGSON, 1959, cap. IV). Deleuze, nesse sentido, sustenta uma filosofia para a qual não há possibilidades não realizáveis, porém, apenas virtualidades ainda não atuais.

A incompossibilidade indica um ponto de disjunçáo que faz aparecer uma singularidade. No entanto, como percebemos ao longo de toda a filosofia de Deleuze, a disjunção constitui uma das sínteses fundamentais de produção do real (CARDOSO JR, 2007) e não opera uma distinção, como em Leibniz e Frémont, entre o real e o que não o é. Essa distinção se estabelece entre o que devém atual e o mundo virtual que o atravessa ou que está envolvido nele. De acordo com Deleuze, cada atual contém de alguma forma todos os que estáo em disjunçáo com ele e que permanecem em estado virtual. Ressalta-se, aqui, a distinção entre possível e virtual, para Deleuze. Enquanto o possível representa o que, não sendo contraditório, se erige como alternativa ao real, o virtual constitui o que está incluído em alguma coisa, não sendo, pois, alternativa, senão fazendo parte do atual (DELEUZE, 1988, p. 140 y ss.; DELEUZE, 2006, p. 43-68; CARDOSO JR, 2007). Portanto, as disjunçóes entre o atual e o virtual referem-se a uma forma complexa de inclusão, daí o novo sentido que Deleuze atribui à incompossibilidade.

Para Frémont, entretanto, a disjunção própria da incompossibilidade não é sintética e, como analisamos acima, representa a escolha do melhor dos mundos possíveis. Conforme a autora, tal disjunção é parte do núcleo fundamental em que opera o princípio de economia. Apesar da tensão entre ambos os autores, nesse tema, destaca-se o fato de que Frémont aprecia a nova abordagem que Deleuze faz desse conceito, no capítulo V de Le Pli. Com efeito, Deleuze critica a tendência de diversos comentadores do século XX à redução da incompossibilidade a um mecanismo de contradição (COUTURAT, 1901; GUEROULT, 1967; MARQUES, 2004, 2006). Esta se define, ao contrário, como posição de uma relação de inclusão complexa, na qual o pertencimento de um indivíduo a seu mundo se produz na divergência a respeito de infinitos outros mundos possíveis, segundo Leibniz. Daí a dificuldade em reduzir a incompossibilidade a uma relação de contraposição (DELEUZE, 1988; FRÉMONT, 2003; DANOWSKI, 2004, 2012; MONTENEGRO, 2013). Frémont e Deleuze coincidem, dessa forma, ao sustentarem que "[...] a incompossibilidade é uma diferença e não é uma negação" (DELEUZE, 1991 [1988], p. 94 apud FRÉMONT, 2003, p. 201) 24.

24 "[...] l'incompossibilité est une différence et une divergence, non une négation" (DELEUZE, 1988, p. 79-80). 


\section{VICE-DICÇÃo}

Deleuze introduz esse neologismo em uma palestra ministrada para a Société Française de Philosophie, em 1967, intitulada La méthode de dramatisation. Ao que parece, ele lia com atenção a descrição que Belaval faz do fenômeno de homogonia presente na matemática leibniziana. A vicedicção, com efeito, visa demonstrar quão longe está Leibniz de pensar a divergência entre os infinitos mundos possíveis em termos de contra-dicção. Todavia, Deleuze crê que as proposiçôes relativas à definição do lugar de um indivíduo em um mundo possível dependem de um percurso pelas diversas possibilidades de inclusão virtual de infinitos mundos no indivíduo e não da exclusão dessa relação. Até aqui, a vice-dicção coincide com a abordagem do conceito de incompossibilidade. No entanto, ele acrescenta uma questáo fundamental: a vice-dicção é um procedimento que permite constituir a essência como uma declinação do inessencial (DELEUZE, 2002 [1967]). A variação de singularidades e acontecimentos constitui uma verdadeira nebulosa inessencial. De acordo com Deleuze, aliás, a vice-dicção consiste em percorrer "[...] as multiplicidades, enumerar os 'casos' que lhes correspondem [...] ordená-los em séries em que o singular se erige sobre o fundo dos ordinários, em que as essências elas mesmas aparecem como casos particulares da declinação do inessencial.” (SIMONT, 1997, p. 268, tradução nossa) ${ }^{25}$.

O texto de Belaval encontra-se no monumental estudo de 1960, dedicado aos contrastes entre Descartes e Leibniz, Leibniz, critique de Descartes. A referência à homogonia faz parte de um capítulo dedicado à análise infinitesimal, onde se faz referência aos fenômenos matemáticos de variação e desaparição quantitativa (Cap. VI). Isso coloca a reflexão diante do problema de constituir espécies e gêneros bem delimitados, pois o que, a rigor, acontece na variação - que dá conta da continuidade no universo - é que a passagem ao limite pode transformar algo em uma espécie do gênero contrário. Como dar conta, por exemplo, da íntima vinculação do ponto e da linha, senão reconhecendo uma passagem que transforma, por meio de uma variação contínua, um no outro?

De qualquer forma, nem o marco é uma parte do demarcado, nem a secção do seccionado: tais duplas não são homogêneas. Elas são homógonas. Os homogêneos vêm a ser semelhantes uns aos outros por transformação, por exemplo, da curva na reta. Mas o que define os homógonos é que um

25 "[...] les multiplicités, y énumérer des " cas" [...], les ordonner en séries où le singulier sérige sur fond de l'ordinaire, où les essences elles-mêmes apparaissent comme cas particuliers de la déclinaison de l'inessentiel". 
gênero possa se transformar, por uma mudança continua, em, por assim dizer, na espécie oposta, em "uma espécie do gênero contrário" - tempoinstante, espaço-ponto, marco-demarcado, ângulo-ponto, movimentorepouso, desigualdade-igualdade, etc. - e que, em virtude da continuidade da mudança, esta quase-espécie possa ser tratada como o gênero, o exclusivo como inclusivo. Só que, reitera Leibniz, isto não é mais do que uma figura filosófico-retórica, uma maneira aceitável de falar, como um caso particular distinguido frente ao caso geral (contra-distinctio). De fato, nos encontramos num domínio onde o princípio do terceiro excluído - definido a partir do princípio de identidade - deve suspender sua jurisdição. O princípio de contradição, enquanto não se aplica imediatamente senão à identidade A é A, exige uma análise terminável: o princípio do terceiro excluído não poderia, portanto, ser demonstrativo no que concerne às progressóes dos homógonos ou, se se prefere, do contínuo cuja análise é por natureza interminável. (BELAVAL, 1960, p. 333-334, tradução nossa). ${ }^{26}$

Inspirada também no conceito de homogonia, Frémont define a vice-dicção como subsunção sob o caso do que por essência está excluído (FRÉMONT, 2003, p. 34). Engendrar ordens regulares com as respectivas leis depende, então, de casos extraordinários que, produto de que sustentam uma relação de exclusão ou tensão com tais ordens, são capazes de, através da inclusão, desempenhar um papel fundamental nessa gênese (BELAVAL, 1960, p. 333 e ss.; IKEDA, 2011). Daí a linha ortogonal que traçam as singularidades no problema da criação, por exemplo. É o caso de Cristo no mundo, ou do ponto na linha reta.

No primeiro, Frémont investe esforços de pesquisa importantes para mostrar que a encarnação de Deus constitui uma situação extraordinária, cujo estatuto hesitante - ao mesmo tempo dentro e fora do sistema de harmonia

\footnotetext{
${ }^{26}$ "De toute façon, ni la borne n'est une partie de ce qui est borné, ni la section du sectionné : de tels couples ne sont donc pas homogènes. Ils sont homogones. Les homogènes, une transformation les rend semblables l'un à l'autre, par exemple, la courbe à la droite, mais ce qui définit les homogones, c'est qu'un genre peut s'y transformer, par un changement continu, dans, pour ainsi dire, l'espèce opposée, dans "une espèce de son contradictoire" - temps-instant, espace-point, borné-borne, angle-point, mouvement-repos, inégalitéégalité, etc. - et qu'en vertu même de la continuité du changement cette quasi-espèce peut être traitée comme le genre, l'exclusif comme l'inclusif. Seulement, répète Leibniz, ce n'est que par une figure philosophicorhétorique, une manière tolérable de parler, comme un cas particulier dans les cas général distingué en regard (contra-distinctio). En fait, nous nous trouvons en un domaine où [...] le principe du tiers exclu - définit à partir du principe d'identité - doit suspendre sa juridiction. Le principe de contradiction, ne s'appliquant immédiatement que à l'identité A est A, exige une analyse terminable : le principe de tiers exclu ne saurait donc être démonstratif en ce qui concerne les progressions des homogones ou, si l'on préfere, le continu dont l'analysée est par nature interminable».
} 
pré-estabelecida - o transforma em uma das linhas fundamentais da gênese do sistema. Nesse caso, a razão suficiente encontra seu lugar no amor de Cristo, ou seja, em um modelo de elos transversais, notadamente referidos ao vinculum substantiale, que propicia comunhão dos seres criados (FRÉMONT, 2003, p. 217-224). O acordo entre corpo e alma, pressuposto pela harmonia pré-estabelecida, é superado por uma exceção que demonstra a união material dos dois no corpo de Cristo - o que serve de modelo para pensar o liame transversal que entretecem os corpos de todas as criaturas (FRÉMONT, 1999, p. 43-45). O segundo caso é citado dentre muitos outros exemplos matemáticos que Frémont (2003, p. 21-23) utiliza como modelos para sua proposta metafísico-teológica. Não obstante, chama a atenção o fato de que a comentadora declara explicitamente sua preferência pelos referentes teológico e jurídico, por serem estes mais adequados à análise de instâncias excepcionais que estão no limite do razoamento demonstrativo que domina nas outras áreas do saber (FRÉMONT, 2003, p. 8, n. 2). Contudo, a presença na sua obra dos casos matemáticos que tratam de instâncias indecidíveis é quase tão relevante como a citação de exemplos teológicos ou jurídicos.

Ora, essa ressonância matemática é também resultado da natureza das questôes que estão em jogo no sistema leibniziano. Como Leibniz reflete, em uma carta dirigida ao matemático francês Pierre Varignon, toda essa ordem de problemas responde às complexidades próprias do princípio de continuidade, verdadeiro responsável pela variação que está por trás da passagem ao limite, implicada no fenômeno de homogonia.

Ora, visto que a lei de continuidade exige que, quando as determinaçôes essenciais de um ser se aproximam às de outro, também, consequentemente, todas as propriedades do primeiro devem se aproximar gradualmente às do último, é necessário que todas as ordens de seres naturais não formem senão uma única série; na qual os pontos de começo e término das diferentes classes $[\ldots]$ estejam tăo próximos uns dos outros que seja impossível fixá-los pelos sentidos e pela imaginação: todas as espécies que delimitam ou que ocupam, por assim dizer, as regióes de inflexão e de torção acabam sendo equívocos e dotados de caracteres que podem se relacionar igualmente com as espécies vizinhas. (LEIBNIZ, 1972 [1707], p. 377-378, tradução nossa) ${ }^{27}$.

\footnotetext{
27 "Or, puisque la loi de la continuité exige que, quand les déterminations essentielles d'un être se rapprochent de celles d'un autre, qu'aussi en conséquence toutes les propriétés du premier doivent s'approcher graduellement de celles du dernier, il est nécessaire que tous les ordres des êtres naturels ne forment qu'une seule chaîne dans laquelle les different classes [...] tiennent si étroitement les unes aux autres qu'il est impossible aux sens et à l'imagination de fixer précisément le point où quelqu'un commence ou finit : toutes les espèces qui bordent ou qui occupent, pour ainsi dire, les régions d'inflexion et de rebroussement, devant être équivoques et douées de caractères qui peuvent se rapporter aux espèces voisines également».
} 
Segundo Frémont, a vice-dicção (sive homogonia) abre a possibilidade de pensar de forma local casos capazes de determinar a gênese de um conjunto em relação ao qual estão em tensão. Daí a importância desse conceito na construção de SIR. De fato, a estratégia de leitura empreendida nessa obra, bem como a determinação do conceito de singularidade, depende da vicedicção. Donde sua afirmação: "A singularidade não advém da oposição de dois princípios, mas da coincidência, no mesmo lugar, de uma lei de conjunto e de um elemento que a coloca em xeque. Em outros termos: trata-se da inclusão de uma irregularidade local em uma ordem global dado que, não obstante, a engendrou" (FRÉMONT, 2003, p. 34, tradução nossa) ${ }^{28}$.

Apesar do entusiasmo expressado por Frémont (2003, p.34, n.49) no começo de SIR - através de uma extensa nota dedicada ao conceito de vicedicção, cumpre indicar que há diferenças importantes, entre um e outro autor, a respeito do uso e conotaçóes do conceito deleuziano. Talvez a diferença esteja novamente no ponto de conflito que surgiu insistentemente a propósito dos tópicos anteriores: a questão teológica.

Em Deleuze, podemos identificar três etapas na abordagem do conceito. A primeira define a essência como um caso do inessencial. A descrição da multiplicidade de acontecimentos e sua variação desenha um âmbito de inclusão que define uma identidade determinada e suas propriedades, gerando com isso a relação que caracteriza a essência (DELEUZE, 1967, p.133, 1968). A segunda descreve o procedimento leibniziano de passagem ao limite, na tentativa de assegurar a continuidade das séries do mundo. A singularidade, no transe de variação, estabelece relaçóes de vizinhança, permitindo a prolongação que dá lugar aos fenômenos de convergência os quais explicam a continuidade no mundo (DELEUZE, 1968, p. 245-246). Finalmente, a terceira etapa evidencia uma aproximaçáo maior ao problema da incompossibilidade ou da disjunção dos diferentes mundos possíveis (DELEUZE, 1988, p. 80).

Frémont, entretanto, cria uma noção que difere em certos detalhes do uso deleuziano. A princípio, é relevante salientar que se trata da tradução do termo matemático de homogonia que, na comentadora francesa, atinge um tratamento teológico-jurídico ${ }^{29}$. Ao estruturar essa nova noção, ela pretende afinar o

\footnotetext{
28 "La singularité n'advient pas de l'opposition de deux principes, mais par la coïncidence, au même endroit, d'une loi d'ensemble et d'un élément qui la tient en échec; en d'autres termes: de l'inclusion d'une irrégularité locale dans un ordre global donné qui pourtant l'a engendrée».

${ }^{29}$ Cumpre lembrar que a metafísica leibniziana se organiza em torno dos elos e trânsitos que o autor mantém com os mais diversos âmbitos da ciência. Para Frémont, constituem referentes importantes
} 
procedimento jurídico de construção de casos por analogia, pretendendo, desse modo, se manter fiel ao sentido original leibniziano. Isso autoriza a pensar a inclusão, enquanto caso extraordinário, do que essencialmente está excluído de um sistema. Para tanto, é necessária a elaboração de uma analogia capaz de realizar a aplicação da lei universal de forma singular ou extraordinária, mas sem gerar uma contradição entre a regra geral e o caso excepcional, ao qual se objetiva aplicar a lei. Parte importante do argumento central de SIR se desenvolve sobre este assunto: como gerar analogias ou ficçóes que permitam uma aplicação singular da lei universal. Ou seja, casos em que a lei inclui o que estaria excluído em uma aplicação ordinária (FREMONT, 2003, p. 48-61). Quanto a esse assunto, talvez o mais próximo de Deleuze, tendo em vista os comentários positivos que Frémont lhe dedica em SIR, representa, ao mesmo tempo, a maior divergência entre ambos os leitores de Leibniz. De fato, de acordo com Frémont, a constituição detalhada de ferramentas conceituais, que representam inovaçôes importantes na leitura do corpus leibniziano, está destinada, no fundo, a responder às necessidades de defesa contemporânea da teodiceia leibniziana. Consequentemente, o que interessa para a autora é o resgate da defesa do caso jurídico, no qual a singularidade atinge o nível mais complicado e relevante para o sistema filosófico leibniziano: a defesa de Deus. Essa defesa atravessa silenciosamente os diversos momentos do diálogo com Deleuze:

1. Está presente, decerto, no estudo introdutório dedicado à tradução da correspondência de Leibniz com Des Bosses. Conforme discutimos anteriormente, para Frémont, é necessário sustentar a realidade substancial dos corpos na delimitação estrita do âmbito do vinculum. Este, em consequência, não pode ser confundido com a multiplicidade do composto. Assim, a realidade dos corpos é garantida através da afirmação da unidade substantivante do vinculum. Entretanto, por que a insistência? Apenas para resguardar a identidade entre Ser e Uno definida na metafísica tradicional? Esta parece ter sido nossa conclusão provisória. Cabe dizer, apesar disso, que todo o esforço de tradução e comentário visava restabelecer o elo entre o problema do vinculum e a transubstanciação (RUSSEL 1999, p. 47-69). Aliás, o vinculum permite justificar metafisicamente a constituiçáo da realidade física dos corpos, mas não se institui como razão suficiente da organização e sentido dos fenômenos no mundo, a não ser quando remete à comunhão dos corpos

desse trânsito a teologia e os estudos jurídicos de Leibniz. Apesar de a autora declarar o contrário, cabe salientar que o referente matemático atinge o mesmo nível de importância para ela, notadamente em estudos como SIR. 
em Cristo. A eucaristia representa, assim, o momento crucial para pensar a encarnação e o problema metafísico da transubstanciação, conforme a abordagem do problema realizado por Leibniz na correspondência com Des Bosses.

2. A defesa de Deus continua presente no tratamento das questóes relativas à singularidade e à incompossibilidade. Remeter os dois conceitos à questão da economia da escolha divina significa, justamente, colocar o mistério da criação no centro das relaçóes extraordinárias e divergentes que essas duas noçôes abordam. O mistério da criação será, como em Leibniz, a razão suficiente que Frémont busca insistentemente, a fim de assentá-la como referente seguro de esclarecimento para os conceitos estudados. A singularidade fornecia, segundo ela, as vantagens suficientes para transformar o sistema hierárquico da harmonia pré-estabelecida em um sistema horizontal de redes inteligíveis, mas envolvia o risco da desorganização própria do labirinto (FRÉMONT, 1991, p. 110112). Aqui, as singularidades devem se encaixar no ponto de disjunçáo que exclui as divergências e garante a unidade do mundo criado. A incompossibilidade aparece, nesse sentido, como um procedimento que identifica as divergências e as exclui através da decisão divina de criação do melhor dos mundos possíveis. A escolha desse mundo e a distribuição das singularidades que expressam de forma privilegiada os mistérios da criação obedecerão, dessa maneira, ao modelo fornecido pelo princípio de economia, objeto central do debate com Deleuze.

3. Por último, com a vice-dicção, Frémont atinge o refinamento mais alto dos seus procedimentos de pesquisa, pois cria um conceito capaz de descrever a ampla diversidade das formas de hesitação ou inclusão ambígua que apresenta o sistema leibniziano. Cabe ressaltar, ao mesmo tempo, que a definição deste conceito traduz o que, no primeiro estudioso contemporâneo do vinculum, Maurice Blondel (1930), não era mais do que prudência metodológica e ambição controlada. Prudência em não mostrar o vinculum diretamente como parte do sistema, o que o colocava em uma instância-limite, a qual, de forma ambígua, entrava e saía do corpus. E ambição, que insinuava a possibilidade de que o vinculum substantiale fosse considerado como uma tentativa superior de aprimoramento do sistema e, como tal, uma correção da Monadologie. Frémont faz dessas atitudes uma ferramenta de pesquisa que possibilita generalizar aquilo que Blondel se inclinava a fazer somente com o vinculum. Os casos locais, eventualmente 
excepcionais, ganham uma ressonância geral que, através da vice-dicção, esclarece a natureza ambígua das suas relaçóes com as leis que organizam a totalidade do sistema. Dessarte, a vice-dicção ganha uma importância fundamental para apreciar retrospectivamente a tentativa de interpretaçáo de Frémont. A atenção aos meandros da criação, a análise local, o desfile interminável de casos jurídicos, teológicos e matemáticos, fazem parte de uma empresa filosófica necessária e atraente, capaz de mostrar, nos limites do sistema leibniziano, trânsitos, exceçôes e hesitaçôes fecundas.

MONTENEGRO, Gonzalo. Deleuze in dialogue with Frémont: attempts at reading Leibniz. Trans/form/ação, Marília, v. 39, n. 2, p. 147-174, Abr./Jun., 2016.

\begin{abstract}
Gilles Deleuze's research during the 1980s focused on the 17th century German thinker G. W. Leibniz. In 1988, Deleuze published Le Pli, which forms part of a series of works on modern philosophy. This book displays Deleuze's attention to the interpretations of contemporary commentators on modern philosophy, in this case, on Leibniz. In this context, there occurred a brief and important dialogue between Deleuze and Christiane Frémont, the French commentator and translator of Leibniz, with regard to their respective interpretations of the great German philosopher. This article intends to give an account of the main topics present in that conversation. Firstly, we can say they involve 1) the problem of body and the Leibnizian vinculum substantiale, 2) the question of singularities, 3) the principle of economy and incompossibility, and 4) the Deleuzian concept of vice-diction. Our hypothesis in this study is that the readings made by both authors of the German thinker are mutually involved. It is essential, in order to support this hypothesis, to make precise the demarcations of relations between such readings. For this reason, our research will focus on Frémont's study Singularités, individus et relations dans le système de Leibniz (2003) and on Deleuze's work Le Pli (1988). We hope to determine the topics that emerge in the relationship, and to specify convergences and divergences of interpretation.
\end{abstract}

KEYWORDS: Gilles Deleuze, body, singularity, principle of economy, incompossibility, vice-diction.

\title{
REFERÊNCIAS
}

BELAVAL, Y. Leibniz : critique de Descartes. Paris: Gallimard, 1960. . Leibniz : initiation a sa philosophie, Paris: Vrin, 1962.

BERGSON, H. L'évolution créatrice. Paris: PUF, 1959 [1907]. . Matière et memoire. Paris: PUF, 1965 [1939].

BLONDEL, M. Une énigme historique : le 'vinculum substantiale' d'après Leibniz. Paris: Gabriel Beauchesne, 1930.

BOEHM, A. Le 'vinculum substantiale' chez Leibniz: ses origines historiques. Paris: Vrin, 1962. BORGES, J. L. El jardín de los senderos que se bifurcan. In: Ficciones. Madrid: Alianza, 1997. p. 43-48. 
O jardim dos caminhos que se bifurcam. In: Ficções. Tradução de José Barrerios). São Paulo: Bibliotex, 2000. p. 59-68].

CARDOSO JR, H. R. Teoria das multiplicidades e conceito de inconsciente no pensamento de Gilles Deleuze: inconsciente-multiplicidade. São Paulo: UNESP, 2007. p. 11-42.

COUTURAT, L. La logique de Leibniz d'après des documents inédits. Paris: Félix Alcan, 1901.

DANOWSKI, D. A propósito de possibilidade, compossibilidade e incompossibilidade em Leibniz de Edgar Marques. Kriterion, Belo Horizonte, n 109, p.188-190, jun. 2004.

- Predicados como acontecimentos em Leibniz. In: CONGRESO IBEROAMERICANO LEIBNIZ, 1., 2012. Anais... San José, Costa Rica: Universidad de Costa Rica, jul. 2012.

DELEUZE, G. Différence et répétition. Paris: PUF, 1968.

. Logique du sens. Paris: Minuit, 1969.

Foucault. Paris: Minuit, 1986.

. Le pli: Leibniz et le baroque. Paris: Minuit, 1988

. A dobra: Leibniz e o barroco. Tradução de Luiz Orlandi. São Paulo: Papirus, 1991.

. La méthode de dramatisation. In: Lîle déserte et autres textes. Paris: Minuit, 2002.

p. 131-162. (Original 1967).

DUCHESNEAU, F. Leibniz: le vivant et l'organisme. Paris: Vrin, 2010.

FICHANT, M. Da substância individual à Mônada. Analytica. v. 5, n. 1/2, p.11-34, 2000.

FRÉMONT, C. Complication et singularité. Revue de Métaphysique et de Morale, 96e année, n. 1, p. 105-120, jan.-mar. 1991.

. L'être et la relation avec 'Trente-sept Lettres de Leibniz au R.P. Des Bosses'. Paris: Vrin, 1999. ([1 ${ }^{\text {ère }}$ édition 1981).

. Singularités, individus et relations dans le système de Leibniz. Paris: Vrin, 2003.

GUEROULT, M. Leibniz: dynamique et métaphysique. Paris: Aubier-Montaigne, 1967.

IKEDA, S.. Les limites et ses modalités chez Leibniz. In : BREGER, J. et al. (Ed.). Natur und subjekt: IX Internationalen Leibniz-Kongresses. Hannover: Hartmann, 2011. p. 494-503.

LAERKE, M. Deleuzian becomings and Leibnizian Transubstantiation. Pli. The Warwick Journal of Philosophy, n. 12, p. 104-117, 2001.

LAUTMAN, A. Essai sur les notions de structure et d'existence en mathématiques. Paris: Hermann \& Cía, 1938.(Tome I-II)

LEIBNIZ, G.W. Théodicée, In: JANET, P. Oeuvres philosophiques de Leibniz.. Paris: Félix Alcan, 1900 [1710]. (Tome I-II).

. De veritatibus primis [1680]. In : GERHARDT, C.I. Die philosophischen Schriften von Gottfried Wilhelm Leibniz. Berlín: reedição Olms, Hildeshein, 1978. p. 194-197. V. 7. 
Discours de métaphysique et correspondance avec Arnauld. Éd. Georges Le Roy. Paris: Vrin, 1988 [1686].

. 'De la réforme de la philosophie première et de la notion de substance' [1693], 'Système nouveau de la nature et de la comunication des substances' [1695], 'De l'origine radicale des choses' [1697]. In: . Oeuvres choisies. Éd. Lucy Prenant. Paris: Garnier Frères, 1939.

. Nouveaux essais sur l'entendement humain. Paris: Flammarion, 1921 [1704].

. 'Lettre à Varignon' [16/10/1707]. In: Oeuvres de G. W. Leibniz. Éd. Lucy Prenant. Paris: Aubier Montaigne, 1972.

. Trente-sept lettres de Leibniz au R.P. Des Bosses [1706-1716]. Éd. Christiane Frémont. Paris: Vrin, 1999.

. Monadologie. Éd. Émile Boutroux. Paris: Delagrave, 1881 [1714] [Monadologia. Tradução de Fernando Barreto Gallas, 2007. Disponível em: <http://www.leibnizbrasil. pro.br/leibniz-traducoes/monadologia.htm>. Acesso em: 10 out. 2014].

LOPES, L. M. Deleuze e a vice-dicção. Kalagatos: Revista de Filosofia, Fortaleza, CE, v.7, n. 14, p. 111-140, verão 2010.

MARQUES, E. As origens da Incompossibilidade em Leibniz. Cadernos de História e Filosofia da Ciência, Campinas, Série 3, v. 16, n. 1, p. 145-162, jan.-jun. 2006.

. Possibilidade, compossibilidade e incompossibilidade em Leibniz, Kriterion, Belo Horizonte, n. 109, p. 175-187, jun. 2004.

MARTIN, J-C. Variations : la philosophie de Gilles Deleuze. Paris: Payot, 1993.

MONTENEGRO, G. Empirismo transcendental: Génesis y desarrollo de la filosofía de Gilles Deleuze. Bogotá: Bonaventuriana, 2013.

RUSSELL, B. A critical exposition of the philosophy of Leibniz, with an appendix of leading passages. Cambridge: Cambridge University Press, 1900.

SIMONT, J. Essai sur la quantite, la qualite, la relation Chez Kant, Hegel, Deleuze: les Fleurs Noires de la logique philosophique. Paris: L’Harmattan, 1997.

TARDE, G. Monadologie et sociologie, version numérique par Mme Marcelle Bergeron [on line]. (Les Classiques des Sciences Sociales). 2002. Disponível em: <http://classiques.uqac. $\mathrm{ca} /$ classiques/tarde_gabriel/monadologie/Monadologie_et_socio.pdf>. Acesso em: 10 jan. 2015.

Recebido em 07/12/2015

Aceito em 10/02/2016 